\title{
ORGANIZAÇÃO E ESTRUTURA DA EDUCAÇÃO PROFISSIONAL NO BRASIL: DA REFORMA CAPANEMA ÀS LEIS DE EQUIVALÊNCIA
}

\author{
O. M. MEDEIROS NETA ${ }^{1,2,{ }^{*}}$, E. L. M. LIMA ${ }^{2}$, J. K. S. F. BARBOSA ${ }^{3}$, F. L. S. NASCIMENTO ${ }^{4}$ \\ ${ }^{1}$ Universidade Federal do Rio Grande do Norte, ${ }^{2}$ Instituto Federal do Rio Grande do Norte - Campus Natal \\ Central \\ olivianeta@yahoo.com.br*
}

Submetido 22/02/2018 - Aceito 05/06/2018

DOI: $10.15628 /$ holos.2018.6981

\section{RESUMO}

O texto, a partir de uma revisão bibliográfica e de análise documental, analisa a organização e estrutura da Educação Profissional brasileira a partir das Leis Orgânicas de Ensino, na década de 1940, oriundas daquela que ficou mais conhecida como "Reforma Capanema" e das Leis de Equivalência do Ensino, mais especificamente as leis $n^{\circ} 1.076$, de 31 de março de 1950, Lei $\mathrm{n}^{\circ} 1.821$, de 12 de março de 1953 e Lei $\mathrm{n}^{\circ}$ 3.552 , de 16 de fevereiro de 1959. Esta pesquisa dialoga com autores que versam sobre a educação, como Romanelli (1978, 2005), Silva (1980), Cunha (1981) e Manfredi (2002) que apresentam, significativamente, uma gama de questões pertinentes para entender o processo educacional durante o período referenciado. Utilizamos o método exploratório, uma vez que busca apenas levantar informações sobre um determinado objeto, delimitando um campo de trabalho, mapeando as condições de manifestações desse objeto. As concepções estabelecidas para essa pesquisa foram analisadas por meio de uma abordagem qualitativa com predominância de tratamento dos dados através da interpretação histórica. Discutimos a temática tendo como base de explicação o materialismo histórico dialético. Os resultados apontam para uma educação historicamente dual, porém as Leis de Equivalência surgem com a finalidade de suprir as limitações existentes nas Leis Orgânicas do Ensino que já não respondiam às aspirações da sociedade vigente, em plena expansão econômica e industrial.

PALAVRAS-CHAVE: Educação Profissional no Brasil, Reforma do Ensino, Leis Orgânicas do Ensino, Leis de Equivalência do Ensino.

\section{ORGANIZATION AND STRUCTURE OF THE PROFESSIONAL EDUCATION IN BRAZIL: FROM THE CAPANEMA REFORM TO THE EQUIVALENT LAWS}

\begin{abstract}
The text, based on a bibliographical review and documentary analysis, investigates the organization and structure of the Brazilian Professional Education from the Organic Laws of Teaching in the 1940s, which became better known as "Capanema Reform" and from the Equivalence Laws of Teaching, more specifically the Law no 1.076, from March 31st of 1950; Law no 1.821, from March 12th of 1953 and the Law no 3.552, from February 16th of 1959. This research dialogues with authors that deal with Education, such as Romanelli (1978, 2005), Silva (1980), Cunha (1981) and Manfredi (2002) who presente a range of meaningly relevant questions to understand the educational process during the referenced period. It was used the exploratory
\end{abstract}

method, since it seeks only to gather information about a given object, delimiting a field of work, mapping the conditons of manifestations of that object. The conceptions established for this research were analyzed through a qualitative approach with a predominance of data treatment through historical interpretation. The theme was discussed on the basis of historical dialectical materialism. The results point to a historically dual education, but the Equivalence Laws arise with the purpose of filling the existing limitations in the Organic Laws of Teaching that no longer responded to the aspirations of the current society in full economic and industrial expansion.

KEYWORDS: Professional education in Brasil, Teaching reform, Organic Laws of teaching, Equivalence laws of teaching. 


\section{APRESENTAÇÃO}

O Brasil tem demonstrado em sua história os passos e a direção que a educação tem seguido no sentido de privilegiar claramente as elites condutoras e o trabalho intelectual em detrimento do trabalho manual e a escolarização das camadas populares, menos favorecida econômica e socialmente.

Historicamente, o trabalho manual acabou sendo destinado às classes menos favorecidas economicamente e aos pobres e abandonados, desvalidos da sorte, enquanto o trabalho intelectual era reservado aos homens livres, pertencentes à elite da sociedade brasileira, como aponta Cunha $(2005$, p. 2):

Embora saibamos que houve trabalho livre desde o início da colonização, assim como a escravatura persistiu de fato, ainda que não de direito, depois de 1888 , cumpre destacar que a sanção jurídico-política operou como um importante elemento de reforço das representações sociais que depreciavam o trabalho manual. Considerada coisa própria de escravo, a atividade artesanal e a manufatureira acabavam abandonadas pelos trabalhadores brancos e livres, de modo que elas iam inexoravelmente para as mãos dos africanos e seus descendentes.

A dicotomia social presente na história do nosso país imprimiu também suas marcas na formação do sistema educacional brasileiro ao assegurar, por meio de instrumentos legais, a manutenção de direitos àqueles oriundos das classes sociais detentoras dos meios de produção e consolidar o fosso existente entre os mais pobres, aos quais seria destinada uma educação puramente técnica e voltada para um fim em si mesma (o ingresso no mercado de trabalho) e o mais ricos, aos quais deveriam ser dadas amplas condições para o acesso ao ensino superior.

Desta forma, os preceitos legais, especialmente aqueles decorrentes da Reforma Capanema, impossibilitavam a livre ascensão social das classes mais pobres, mantendo a educação propedêutica e a profissional direcionadas para caminhos diferentes, já que, a elite tinha acesso ao ensino propedêutico, enquanto que as classes menos favorecidas em ficavam restritas à educação estritamente profissional.

Neste artigo, analisamos a organização e estrutura da Educação Profissional Brasileira a partir das Leis Orgânicas de Ensino, na década de 1940, oriundas daquela que ficou mais conhecida como "Reforma Capanema" e as Leis de Equivalência do Ensino, mais especificamente as Leis da década de 1950, a saber: Lei $n^{\circ}$ 1.076, de 31 de março de 1950, Lei $n^{\circ} 1.821$, de 12 de março de 1953 e Lei $n^{\circ}$ 3.552, de 16 de fevereiro de 1959 com a intenção de evidenciar em que se limitavam as leis anteriores a estas, em questão, para assim aprofundar um pouco mais a respeito das raízes desses problemas educacionais que, apesar de longínquos, não deixam de ser atuais.

É inegável que questões políticas, levando-se em consideração as classes mais pobres, fortalecem a ideia de que elas necessitam de trabalho manual e, anteriormente, de educação profissional, para - de forma silenciosa, implantar (ou fortalecer) o regime servil, acarretando, 
por óbvio, condições de subalternação nas relações trabalhistas, pois aquelas, sem poder de escolha, sofrem a imposição legal/regulamentar dos mandatários (pertencentes à cúpula dos Poderes), principalmente do Poder Legislativo Federal, representado pelo Congresso Nacional, que tem como uma de suas funções constitucionais: a elaboração de atos normativos (leis, decretos), que, no caso da educação, trazem fortes consequências concretas: a divisão da educação propedêutica e profissional, a divisão de classes.

A análise bibliográfica e documental foi a base da metodologia utilizada nessa pesquisa, que percorre os principais marcos históricos da Educação Profissional, a partir da Reforma de Capanema, na década de 1940 até a promulgação das Leis de Equivalência que surgem para suprir as lacunas existentes nas Leis Orgânicas do Ensino. Quanto aos seus objetivos, é uma pesquisa exploratória, uma vez que busca apenas levantar informações sobre um determinado objeto, delimitando um campo de trabalho, mapeando as condições de manifestações desse objeto. E as concepções estabelecidas para essa pesquisa foram analisadas por meio de uma abordagem qualitativa.

Empregamos como método a interpretação histórica de acordo com Rüsen (2009, p. 129) a "interpretação histórica como uma metodologia que remete perspectivas teóricas ao passado, nas quais o passado reveste do caráter de histórico, com o conteúdo informativo das manifestações empíricas, mediante as quais esse passado se faz perceptivelmente presente.

Após estudo das Leis de Equivalência, realizamos a análise dos dados seguindo as etapas da leitura exploratória, seletiva, analítica e interpretativa proposta por Gil (2010).

Para tanto, esta pesquisa dialoga com autores que versam sobre a educação, como Romanelli (1978, 2005), Silva (1980), Cunha (1981) e Manfredi (2002) que apresentam, significativamente, uma gama de questões pertinentes para entender o processo educacional durante o período aludido.

Dessa forma, a presente investigação trata da finalidade geral que tinha a Educação Profissional nas décadas de 1940 e 1950 a partir da interpretação de suas leis. Também destacamos os entraves curriculares para o acesso ao ensino superior, dos estudantes oriundos de escolas industriais e dos cursos técnicos.

As Leis Orgânicas do Ensino, conhecidas também como Reforma Capanema, tratam das transformações projetadas no sistema educacional brasileiro envolvendo os seguintes ramos do ensino: secundário, industrial, comercial, agrícola, normal e primário.

Já na década de 1950, surgem as Leis de Equivalência do Ensino, que aparecem para suprir as limitações existentes nas Leis Orgânicas do Ensino que já não respondiam às aspirações da sociedade vigente, em plena expansão econômica e industrial.

Tendo em vista promover a equivalência dos certificados de conclusão dos estudos nas escolas técnicas e a democratização do acesso ao ensino superior, as três "leis" publicadas em 1950, 1953 e 1959 se propõem a estabelecer mudanças fundamentais na organização do sistema educacional brasileiro, especialmente no tocante ao primeiro e segundo ciclos do ensino médio, promovendo inclusive transformações conceituais no ensino técnico. 
Face a essa realidade histórica, apresentamos a continuação, mesmo que de forma sucinta, o que representou as Leis Orgânicas do Ensino para a Educação Brasileira e, continuamente, os avanços da Educação Brasileira com a promulgação das Leis de Equivalência do Ensino.

\section{AS LEIS ORGÂNICAS DO ENSINO (A REFORMA CAPANEMA)}

Durante o período de 1937 e 1946, conhecido como Estado Novo, o Brasil esteve sob a ditadura de Getúlio Vargas. Toda a legislação desse período foi marcada pela articulação junto aos ideários nacionalistas de Getúlio Vargas e seu projeto político ideológico. Nesta época, entra em vigor a normatização do ensino brasileiro com a Reforma Capanema ${ }^{1}$ (nos anos de 1942 a 1946), sob o nome de Leis Orgânicas do Ensino (Decretos-Lei), no qual, estrutura o ensino industrial, reforma o ensino comercial, traz alteração no ensino secundário e cria o Serviço Nacional de Aprendizagem Industrial - SENAI.

Na Era Vargas, houve fortalecimento da dualidade da educação, já que existia forte restrição em relação ao acesso ao ensino superior: egressos da educação média profissionalmente somente poderiam ter acesso aos cursos de nível superior da mesma carreira, ou seja, não havia poder de escolha, eleger carreiras diferentes.

Em relação aos alunos do ensino secundário, não havia restrição alguma, já que eles tinham acesso ao nível superior. Percebe-se, inclusive, na elaboração dos decretos-lei principalmente do Decreto-Lei do Ensino Secundário, forte influência fascista, pois havia robusta restrição da educação superior às classes dominantes, já que, a partir da obtenção de conhecimento e do privilégio das informações, ela poderia se manter no poder e, maximizar a distância entre elas e as classes mais pobres, subalternas.

As Leis Orgânicas do Ensino foram deliberadas através de Decretos-Lei, nos quais possuem força de lei emanados do poder executivo, correlatos às nossas Medidas Provisórias. Conforme Romanelli, (2005), a referida reforma se limitava, uma vez que não foi abrangente, pois não atendeu toda a educação brasileira. Os decretos-lei se referiam a cada nível de ensino, em separado e isoladamente. Como bem explica, Manfredi (2002), a Lei Orgânica do Ensino tinha a finalidade velada em promover grupos políticos, com clara propensão voltada para agraciar empresários, em detrimento daqueles que pertenciam às classes mais pobres da população.

Os currículos foram repensados e o ensino secundário ficou em oposição ao profissional, com existência de articulação efêmera entre eles, numa época que havia a necessidade de formação de mão de obra qualificada. Para tanto, a mesma autora sinaliza que o curso secundário foi designado para formar os dirigentes da nação, já os ramos da educação profissional foram constituídos para os seguintes setores da produção: a) primário, para o ensino agrícola; b) secundário para o ensino industrial; c) terciário para o ensino comercial e o d) ensino normal para a formação de professores.

\footnotetext{
${ }^{1}$ MENEZES, Ebenezer Takuno de; SANTOS, Thais Helena dos. Verbete Reforma Capanema. Dicionário Interativo da Educação Brasileira - Educabrasil. São Paulo: Midiamix, 2001. Disponível em: <http://www.educabrasil.com.br/reforma-capanema/>. Acesso em: 15 de fev. 2018.
} 
De acordo com Romanelli (2005, p. 154), no ano de 1942 começaram a ser reestruturadas alguns ramos do ensino, mesmo que de forma parcial, porém, para aquela ocasião, a exigência era de reformas mais abrangentes. Destacamos, também, que nem todas essas reformas foram realizadas sob o Estado Novo, sendo postos em execução, durante os três últimos anos do Estado Novo, somente os seguintes decretos-lei:

a) Decreto-lei $n^{\circ} 4.073$, de 30/01/1942, que estruturou o ensino industrial;

b) Decreto-lei $n^{\circ} 4.048$, de 22/01/1942, que criou o Serviço Nacional de Aprendizagem Industrial;

c) Decreto-lei $n^{\circ} 4.244$ de 9/04/1942, que regulou o ensino secundário em dois ciclos: 0 ginasial, com quatro anos, e o colegial, com três anos;

d) Decreto-lei $n^{\circ} 6.141$, de 28/12/1943, que reestruturou o ensino comercial.

Os Decretos acima foram criados na gestão de Gustavo Capanema ${ }^{2}$, durante o tempo em que Vargas era Presidente da República. Logo após a sua queda, a reforma estendeu-se com outros decretos-lei, durante o Governo Provisório de José Linhares, com o então Ministro da Educação, Raul Leitão da Cunha. Os decretos-lei ficaram estabelecidos da seguinte maneira:

a) Decreto-lei n. 8.529, de 02 de janeiro de 1946, que organizou o ensino primário a nível nacional supletivo, com duração de dois anos, destinado a adolescentes a partir dos 13 anos e adultos;

b) Decreto-lei 8.530, de 02 de janeiro de 1946, que organizou o ensino normal;

c) Decretos-lei n 8.621 e 8.622, de 10 de janeiro de 1946, que criaram o SENAC;

d) Decreto-lei n. 9.613 de 20 de agosto de 1946, que organizou o ensino agrícola.

Com todos esses decretos-lei, ficavam assim reestruturado o ensino primário e médio brasileiro. Prosseguimos com uma análise das Leis de Equivalência do Ensino dada a sua representatividade para a evolução do ensino brasileiro.

\section{AS LEIS DE EQUIVALÊNCIA: A EDUCAÇÃO BRASILEIRA NA DÉCADA DE 1950}

A década de 1950 foi marcada pelo forte crescimento do capital industrial brasileiro. A economia nacional apesentava fortes sinais de desenvolvimento, especialmente no tocante à implantação de indústrias (automóveis, eletrodomésticos, etc.) e a consequente criação de novos postos de trabalho que demandavam agora, novos conhecimentos.

No entanto, o currículo praticado até então na formação dos trabalhadores datava do início da década de 1940 e já não respondia aos anseios das demandas internas. Segundo Cunha (2005, p. 153):

A rigidez da 'lei' orgânica do ensino industrial, que estabeleceu de antemão cursos, currículos e modos de funcionamento escolares padronizados para todos

\footnotetext{
${ }^{2}$ Gustavo Capanema foi o homem que representou a política e os ideais do Estado Novo na cultura e na educação brasileira, nesse período. Capanema foi ministro da Educação e Saúde de Vargas, entre os anos de 1934 a 1945, quando realizou obras importantes, entre as quais se destaca a criação de órgãos nacionais como a Universidade do Brasil, atual Universidade Federal do Rio de Janeiro (UFRJ), a Secretaria do Patrimônio Histórico e Artístico Nacional (SPHAN) e o Instituto do Livro. É possível encontrar mais informações ao seu respeito pelo site http://www.educacaopublica.rj.gov.br/biblioteca/educacao/0069_10.html
} 
os cursos básicos industriais, impedia a adaptação do ensino às transformações da economia. Essa rigidez assumiu maior gravidade na década de 1950 quando setores inteiros da economia foram implantados [...] e outros expandidos.

Neste sentido, no dia 31 de março de 1950 foi promulgada a Lei n.1.076 (BRASIL, 1950), a primeira das "Leis de Equivalência do Ensino".

Segundo Cunha (2005, p. 158) esta lei é de fundamental importância no sentido da busca pela total equivalência e democratização do acesso ao ensino superior, na medida em que "[...] foi decisiva para a transformação dos cursos básicos industriais, de portadores de um conteúdo quase que exclusivamente profissional, para um conteúdo cada vez mais geral, abrindo, assim, caminho para a sua própria extinção ao fim da década de 1950" (CUNHA, 2005, p. 158).

Esta lei, assegurou a equivalência do certificado de conclusão dos cursos técnicos comerciais ao 20 ciclo do secundário, permitindo ao seu portador candidatar-se a quaisquer cursos superiores, mediante exames vestibulares, não apenas àqueles cursos de nível superior diretamente relacionados ao curso técnico de comércio ora concluído, como era praticado até então.

Novas garantias, mas com ressalvas, conforme Cunha (2005, p. 156):

[...] o direito de matrícula nos cursos clássico e científico (2 ciclo do ensino médio, ramo secundário) aos egressos do curso industrial, comercial ou agrícola do 1 을 ciclo de ensino médio, mas estabeleceu restrições como a aprovação em exames das matérias do ginásio não estudadas naqueles cursos - eram os "exames de complementação". Esses exames seriam realizados em escolas federais, reconhecidas ou equiparadas. Os concluintes do 10 ciclo do ensino normal continuavam podendo se candidatar apenas ao 2 ㅇ ciclo do mesmo ramo.

Começava assim, um processo de mudança, mesmo que de forma ainda tímida, na organização do sistema educacional brasileiro. Estas transformações continuaram em curso e três anos depois, em 12 de março de 1953, a lei n. 1.821 garantiu a possibilidade de ingresso no 20 ciclo do ensino secundário também aos concluintes do 1 o ciclo do ensino normal (preenchendo assim uma lacuna deixada pela lei anterior) e aos egressos dos cursos de formação de oficiais das polícias militares (BRASIL, 1953a).

Esta lei, embora ainda não promovesse a equivalência plena, também tornou possível aos concluintes do 2 o ciclo dos cursos industrial, agrícola e normal, bem como aos egressos de seminários religiosos (CUNHA, 2005) a inscrição nos exames vestibulares de quaisquer cursos. Tornou claro quais eram os denominados cursos relacionados para efeitos de ingresso no ensino superior dos concluintes da escola técnica: engenharia, química industrial, arquitetura, matemática, física, química e desenho.

Ficou definido também que o egresso da escola técnica deveria também demonstrar ter cursado determinadas disciplinas de cultura geral ou certificar sua aprovação em exames destas disciplinas em estabelecimentos de ensino secundário federal ou equiparado. 
A segunda Lei de Equivalência, Lei $n^{\circ} 1.821$, de 12 de março de 1953, no entanto, ainda mantinha as restrições impostas à transferência de estudantes entre os ramos e os ciclos do grau médio e entre estes e o superior.

Contraditoriamente, em outubro deste mesmo ano, o decreto n. 34.330 (BRASIL, 1953b) estabeleceu restrições ao que estava enunciado pela lei em seu art. 20 que garantia aos egressos dos cursos profissionais o direito à matrícula na primeira série de qualquer curso superior, desde que atendidas as exigências do exame vestibular e o cumprimento dos requisitos específicos para cada caso.

O decreto estabeleceu os cursos aos quais os egressos dos cursos profissionais poderiam candidatar-se. Sendo assim:

[...] os egressos dos cursos técnicos industriais poderiam se candidatar apenas aos cursos das escolas de engenharia, de química e de desenho, estes últimos das faculdades de filosofia, ciências e letras (BRASIL, 1953b).

É perceptível claros avanços e retrocessos no caminho da total equivalência dos cursos técnicos. Intensas discussões políticas são empreendidas, culminando com a realização da I Mesa-redonda Brasileira de Educação Industrial, realizadas em São Paulo, Belo Horizonte e Salvador cujas proposições resultaram no anteprojeto de lei aprovado em 16 de fevereiro de 1959, a Lei n. 3.552.

A terceira Lei de Equivalência, Lei $n^{\circ}$ 3.552, de 16 de fevereiro de 1959, mais conhecida como Lei da Reforma Industrial (BRASIL, 1959), propõe mudanças estruturais no sistema educacional brasileiro. Composta por 36 (trinta e seis artigos), propõe mudanças administrativas, curriculares e pedagógicas, na organização das Escolas Industriais do país.

No cenário descrito por Medeiros (2011, p.132), o Brasil vivenciava intensas transformações políticas, sociais e econômicas:

Dos anos 50 ao começo dos 60, a indústria de bens de capital crescera juntamente com a produção de insumos básicos, como aço, petróleo, metais não ferrosos, celulose e papel. Nessa última fase, que compreendera, em grande medida, a execução do Plano de Metas do governo Juscelino Kubistchek (19561961), o país se concentrara na preparação de uma infraestrutura adequada à industrialização nacional, a partir de grandes investimentos em energia e transporte, que trariam duas consequências imediatas: a transformação do petróleo em insumo energético vital para a economia e o desenvolvimento da indústria automobilística.

Urgia a necessidade de consonância entre a realidade econômica e social da época e as ofertas educacionais das Instituições públicas de educação.

O Manifesto dos Pioneiros da Escola Nova (INEP, 1944) em 1932, já não respondia aos anseios da sociedade brasileira na década de 1950, especialmente no governo de Juscelino Kubitschek (1956-1961), marcado pelo forte crescimento econômico e industrial no Brasil. Neste sentido, Azevedo (1959, p. 205) destaca que: 
Não negamos nenhum dos princípios por que nos batemos em 1932, e cuja atualidade é ainda tão viva, e mais do que viva, tão palpitante que êsse documento, já velho de mais de 25 anos, se diria pensado e escrito nestes dias. Vendo embora com outros olhos a realidade, múltipla e complexa, - porque ela mudou e profundamente sob vários aspectos, - e continuando a ser homens de nosso tempo, partimos do ponto em que ficamos, não para um grito de guerra que soaria mal na boca de educadores, mas para uma tomada de consciência da realidade atual [...].

A necessidade de atualização das ofertas educacionais e currículos dos cursos ofertados pelas escolas industriais, bem como maior flexibilização no acesso ao ensino superior, eram demandas cada vez mais presentes.

Em um cenário educacional marcado por duras críticas ao sistema educacional brasileiro, número extremamente reduzido de escolas técnicas, baixa qualificação e defasada remuneração do corpo docente (AZEVEDO, 1959), entre outros fatores, a escola pública foi apontada como culpada por já não conseguir dar respostas a contento de uma sociedade agora marcada pelo forte crescimento demográfico e crescente processo de urbanização e industrialização.

Contrapondo-se a esta acusação, Azevedo (1959), no Manifesto dos Educadores de 1959, reconhece a necessidade de mudanças estruturais no sistema educacional brasileiro como um todo e sai em defesa da Escola pública ao afirmar que:

Não foi, portanto, o sistema de ensino público que falhou, mas os que deviam prever-Ihe a expansão, aumentar-lhe o número de escolas na medida das necessidades e segundo planos racionais, prover às suas instalações, prepararIhe cada vez mais solidamente o professorado e aparelhá-lo dos recursos indispensáveis ao desenvolvimento de suas múltiplas atividades.

A necessidade de mudanças estruturais na educação brasileira tornava-se, portanto, cada vez mais forte e urgente. Segundo Silva (2012, p. 93):

[...] para o alcance do desenvolvimento tão almejado no país, no contexto dos anos de 1950, era necessária uma nova modalidade de ensino industrial, mais flexível, mais autônoma, que priorizasse as necessidades regionais, o que significava possibilitar às escolas técnicas sintonizar-se com as necessidades das industriais locais.

Em resposta a esta realidade, a Lei no 3.552/1959 foi aprovada e torna-se um marco no sentido da abertura e flexibilização na oferta de cursos dos estabelecimentos de ensino industrial Federais no país. Dentre as mudanças ocasionadas pela aplicação desta Lei, está a transformação das escolas industriais em autarquias, com autonomia didática, administrativa e financeira (BRASIL, 1959), vinculando-se a partir de então, de forma indireta ao Ministério da Educação e Cultura.

Outro ponto fundamental na Lei da Reforma das Escolas Industriais foi a criação do Conselho de Representantes (CR). Órgão colegiado, composto por representantes da escola, da Indústria e de setores da sociedade civil, responsável pela efetiva administração das escolas industriais. 
Segundo Silva (2012, p. 108):

Com a Lei no 3.552 de 1959, ocorre a transferência da função de administrar a escola para o Conselho de Representantes, assegurando ainda o poder de realizar a escolha e nomeação do diretor, após indicação do Conselho de Professores. Altera-se, portanto, a concepção de autoridade antes outorgada a esses profissionais, reduzindo as atribuições do cargo à execução das ações estabelecidas por esse colegiado.

Ainda neste sentido de democratização e maior horizontalidade nas relações administrativas escolares, a criação do Conselho de Professores foi também uma novidade apresentada pela Lei no 3.552/1959. Formada por representantes do corpo docente das Instituições de ensino, este Conselho constituía-se enquanto órgão de direção didáticopedagógica da Escola e estava sob a presidência do Diretor (BRASIL, 1959). Entre suas atribuições, descritas no art. 19 estavam:

a) Eleger seu presidente; b) aprovar o orçamento da despesa anual de escola, 0 qual não poderá destinar mais de $10 \%$ para o pessoal administrativo, nem mais de $50 \%$ para o pessoal docente e técnico, reservando-se o restante para material, conservação do prédio e obras; c) fiscalizar a execução do orçamento escolar e autorizar transferências de verbas, respeitadas as porcentagens da alínea b; d) realizar a tomada de contas do Diretor; e) controlar o balanço físico anual e o dos valores patrimoniais da escola; f) autorizar toda despesa que ultrapasse a cem mil cruzeiros; g) aprovar a organização dos cursos, respeitada a distribuição do currículo elaborado pelo Conselho de Professores; h) aprovar os sistemas de exames e promoções a serem adotados na escola, respeitadas as diretrizes elaboradas pela DEI; i) aprovar os quadros do pessoal docente, técnico e administrativo; j) examinar o relatório anual do Diretor da Escola e o encaminhar, com observações, ao Ministério da Educação e Cultura. (Brasil, 1959).

Em uma prática distinta daquelas verificadas nas Leis Orgânicas, vigentes até então, é possível identificar na construção destes espaços colegiados, uma tentativa de tornar o sistema educacional mais democrático, embora algumas práticas apontem o contrário, como por exemplo o fato de que a presidência do Conselho de professores deveria ser ocupada pelo Diretor do Estabelecimento de Ensino.

A Lei da Reforma do Ensino Industrial orientou também mudanças em relação ao currículo e à oferta de cursos. O curso básico industrial, antes destinado ao ensino de um ofício que necessitasse de longa formação profissional (conforme leis orgânicas), a partir de então, assume características de um curso secundário do primeiro ciclo e com orientação técnica (Cunha, 2005), em uma organização educacional que propõe a ampliação dos fundamentos de cultura e a iniciação em atividades produtivas, conforme descrito em seus objetivos (BRASIL, 1959): 
Art. 10: É objetivo das escolas de ensino industrial mantidas pelo Ministério da Educação e Cultura:

a) proporcionar base de cultura geral e iniciação técnica que permitam ao educando integrar-se na comunidade e participar do trabalho produtivo ou prosseguir seus estudos;

b) preparar o jovem para o exercício de atividade especializada, de nível médio.

O parágrafo único deste mesmo artigo orienta que o ensino deverá atender às diferenças individuais dos alunos, considerando também seus interesses e aptidões. Promove assim, uma quebra de paradigmas a medida em flexibiliza as ofertas de ensino e considera o interesse do estudante.

Neste novo itinerário formativo proposto, os cursos de aprendizagem, destinados a jovens a partir dos 14 anos, cuja aprendizagem de conhecimento elementares os capacitariam para desempenhar ofícios qualificados, garantia o acesso ao curso básico industrial, conforme Art. 3o (BRASIL, 1959):

$\S 1$ 1 Os cursos de aprendizagem terão caráter intensivo e duração variável, nunca menor de vinte meses. $\S 2$ o Os alunos que tenham concluído curso de aprendizagem poderão ingressar em uma das séries do curso básico, mediante verificação prévia de seus conhecimentos.

O curso básico, por sua vez, de educação geral, organizado em quatro séries seria destinado aos alunos concluintes do ensino primário tendo em vista orientá-los para o trabalho ou para o prosseguimento nos estudos (BRASIL, 1959).

Os cursos técnicos assegurariam a formação de técnicos "[...] para o desempenho de funções de imediata assistência a engenheiros ou a administradores ou para o exercício de profissões [...] que exijam um profissional desta graduação técnica" (BRASIL, 1959). Nas duas ou três primeiras séries dos cursos técnicos seriam oferecidas disciplinas de conhecimentos gerais.

As escolas de Ensino Industrial poderiam manter cursos de aprendizagem, básicos ou técnicos, conciliando o ensino de matérias com trabalhos de oficinas.

A Reforma do Ensino Industrial também promoveu a ampliação do tempo para conclusão do curso técnico industrial e a eliminação do vestibular (a não ser nos casos onde o número de candidatos superasse o número de vagas). O ensino técnico noturno, introduzido neste mesmo ano por meio do Decreto n. 47.038 (BRASIL, 1959b), também representou uma mudança significativa no contexto da educação profissional brasileira.

Conforme a Lei Orgânica, o curso básico industrial deveria formar prioritariamente artífices e de forma secundária, candidatos aos cursos técnicos. A partir da lei 3.552/1959 a formação profissional passou para o 2 을 ciclo mantendo-se os cursos de aprendizagem; as práticas de oficinas passaram a ser politécnicas. Enquanto no curso básico as disciplinas de caráter predominantemente geral, nos cursos técnicos eram ofertadas disciplinas de caráter mais especializado. 
A Lei da Reforma do Ensino Industrial, promoveu assim, mudanças fundamentais na construção do currículo nas, então denominadas, Instituições de ensino profissional ao prever a elaboração da proposta curricular a partir do trabalho desenvolvido no Conselho de Professores (Brasil, 1959) e na organização administrativa dos estabelecimentos de ensino industrial por meio da atuação de colegiados como o Conselho de Representantes, por exemplo.

Esta lei, segundo Cunha (2005, p. 160), fez com que "[...] o curso industrial básico perdesse o seu caráter profissional e o curso de aprendizagem fosse reconhecido como o único adequado à formação de operários qualificados, perdendo a posição subordinada que lhe dava a 'lei' orgânica". Promoveu assim, uma mudança conceitual de suma importância na consolidação do ensino técnico no cenário educacional brasileiro, que passou de uma perspectiva de formação exclusiva de artífices para a formação de técnicos. Por meio de uma organização administrativa que se propunha mais democrática, horizontal e transparente, em atendimento às demandas do mercado de trabalho da época, garantir uma formação técnica e propedêutica mais flexível e de acordo com os anseios do seu alunado.

\section{CONCLUSÃO}

Na pretensão de uma organização curricular escolar mais estruturada, as Leis Orgânicas do Ensino aumentaram ainda mais o dualismo do sistema educacional brasileiro, distanciando ainda mais a educação propedêutica e a educação profissional.

Percebemos que o acesso ao ensino superior tornou-se ainda mais cerceado aos estudantes egressos da educação profissional, visto que só teriam acesso a esse nível de ensino diretamente relacionado ao curso profissional de nível médio concluído.

Desde então, muitas foram as mudanças estabelecidas pela sociedade, pela economia nacional e pela política, além da necessidade de mudanças também no currículo dos cursos técnicos e nos caminhos para o acesso ao ensino de nível superior. Para tanto, as Leis de Equivalência criadas uma década após a publicação das Leis Orgânicas tinham o propósito de oportunizar a democratização do ensino através da verticalização de estudos também aos egressos da educação profissional.

Essas leis tinham como objetivo suprir as limitações deixadas pela legislação anterior, promovendo a equivalência dos cursos originário do ensino profissional. Ao estabelecer a equivalência entre os certificados dos cursos oriundos da educação profissional e aqueles do curso colegial secundário, paulatinamente foram introduzidas disciplinas propedêuticas e conteúdo não profissionais nos currículos dos cursos técnicos ofertados pela rede pública de educação.

Historicamente, é possível identificarmos nas leis supracitadas, alguns avanços e continuidade em relação à democratização da educação brasileira, especialmente no que se refere ao ensino superior, uma vez que os estudantes de camadas populares puderam ter acesso às Universidades, antes segregadas apenas aos filhos das classes mais bem favorecidas socioeconomicamente da sociedade brasileira. 


\section{REFERÊNCIAS}

ARANHA, M.L.A. História da Educação. São Paulo, Moderna, 2002.

AZEVEDO, Fernando de. Manifesto dos Educadores: Mais uma Vez Convocados. São Paulo, 1959. Disponível em: <http://www.escolanova.net/pages/convocados.htm> Revista HISTEDBR Online, Campinas, n. especial, p.205-220, ago2006 - ISSN: 1676-2584. Acesso em: 28 dez. 2017.

BRASIL, Ministério da Educação e da cultura. Lei de 31 de março de 1950. Rio de Janeiro. 1950. Disponível em < http://www2.camara.leg.br/legin/fed/lei/1950-1959/lei-1076-31-marco1950-363480-publicacaooriginal-1-pl.html> Acesso em 20 dez.2017.

.Lei 1.821 de 12 de março de 1953. Rio de Janeiro. 1953a. Disponível em: http://www2.camara.leg.br/legin/fed/lei/1950-1959/lei-1821-12marco-1953-366631-publicacaooriginal-1-pl.html . Acesso em 20 dez.2017

Janeiro. 1953b. Disponível em: <http://www2.camara.leg.br/legin/fed/decret/19501959/decreto-34330-21-outubro-1953-326101-republicacao-60374-pe.html>. Acesso em 20 dez. 2017.

. Lei no 3.552, de 16 de fevereiro de 1959. Rio de Janeiro. 1959. Disponível em: <www.planalto.gov.br/ccivil_03/leis/L3552.htm> Acesso em: 20 dez. 2017.

Decreto n.o 47.038, de 16 de outubro de 1959. Rio de Janeiro. 1959b. Disponível em < http://www2.camara.leg.br/legin/fed/decret/19501959/decreto-47038-16-outubro-1959-386194-publicacaooriginal-1-pe.html > acesso em 20 dez. 2017.

CUNHA, Luiz Antônio. O ensino de ofícios artesanais e manufatureiros no Brasil escravocrata. 2ed. São Paulo: UNESP, 2005.

GIL, Antônio Carlos. Como elaborar projetos de pesquisa. 4. Ed. São Paulo: Atlas, 2002

INEP. "Manifesto dos Pioneiros da Escola Nova". Revista brasileira de estudos pedagógicos. - v. 1, n. 1 (jul. 1944). - Rio de Janeiro: Instituto Nacional de Estudos Pedagógicos, 1944 - Publicação oficial do Instituto Nacional de Estudos e Pesquisas Educacionais.

MANFREDI, Sílvia Maria. Educação Profissional no Brasil. São Paulo: Cortez, 2002.

MEDEIROS, Arilene Lucena de. A forja e a pena: técnica e humanismo na trajetória da Escola de Aprendizes Artífices de Natal à Escola Técnica Federal do kRio Grande do Norte. Natal: IFRN, 2011.

RIBEIRO, M. L. História da Educação Brasileira. A Organização Escolar. Campinas, Autores Associados, 2003.

ROMANELLI, Otaíza de Oliveira. História da educação no Brasil 1930-73. Petrópolis, Vozes, 1978.

Petrópolis: Vozes, 2005. História da Educação no Brasil (1930/1973). 29 ed.

RÜSEN, Jörn. Reconstrução do passado/ Jörn Rüsen; tradução de Asta-Rose Alcaide. - Brasília: Editora Universidade de Brasília, 2007. 
SILVA, Maria da Guia de Sousa. Escola para os filhos dos outros: trajetória histórica da Escola Industrial de Natal (1942-1968). Tese (Doutorado) - Universidade Federal do Rio Grande do Norte. Centro de Educação. Programa de Pós-Graduação em Educação. Natal, RN, 2012. 